\title{
MOLDING OF SOIL WATER REGIME UNDER DRIP IRRIGATION IN EGYPT
}

\section{Golovanova *, Mahmoud M. Ali**}

\begin{abstract}
Information about the horizontal and vertical distances by which water spreads in soils under a point source is essential for the design of cost effective and efficient drip irrigation systems. The size of the wetting pattern influenced by many factors, including soil physical properties, soil initial conditions as well as emitter discharge rate, irrigation management, crop root characteristics and evapotranspiration. Models can help to predict soil water movement under point source irrigation for a wide range of soil and environmental conditions and varied design parameters and therefore save time and financial resources compared to field experiments.
\end{abstract}

\section{DRIP IRRIGATION MODELLING}

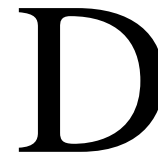
rip irrigation systems consist of point or line source emitters, which are usually operated intermittently. The emitters sometimes interact. For irrigation of row crops, for instance, emitters have to be closely spaced along the laterals to maintain the necessary strip of wetted soil along the row. During irrigation (water infiltration) the water content in the soil changes spatially and temporally. In surface drip irrigation systems, the placement of the emitter directly above the soil surface enables infiltration within a very small area compared to the total area, of the soil surface. Under field conditions, the shape of the wetted volume of soil under a drip emitter is, according to Vermeiren and Jobling (1984), Cote et al. (2003), Gardenas et al. (2005) and Skaggs et al. (2010), influenced by soil texture, soil structure, soil hydraulic properties, anisotropy such as horizontal and vertical permeability and impermeable layers.

\footnotetext{
* land reclamation Dept., Faculty of Environmental Engineering., Moscow state University for Environmental Engineering., Russia

**Soil and Water Dept. (Agric. Eng.), Fac. of Agric., Fayoum Univ., Egypt
} 
The patterns of soil water content depend also on design parameters and management of the system (volume of water applied per irrigation, the rate of application (irrigation frequency), emitter distance (number of drippers), dripper placement (above or below soil surface), lateral positioning with respect to the plant row and initial soil moisture content). Information about the temporal evolution of the wetted volume in a given soil can help in establishing the optimal spacing between the emitters and the irrigation duration as a function of the soil volume where the crop roots are located (Provenzano, 2007). Lamm et al. (2007) mentioned that management, monitoring and modeling of soil water distribution under cropped conditions, also requires information on water uptake patterns by plants. Uptake patterns influence water distribution and are essential for obtaining reliable predictions of water and matric potential distributions within the wetted soil volume. Information on root water uptake is important for design purposes to match application uniformity, emitter spacing and discharge with the extent of plant root systems, and to ensure uniform root accessibility to wetted soil volume.

Lubana and Narda (2001) presented a review of modeling of soil water dynamics under drip emitters, and pointed out that there is still limited knowledge about water movement in soil in response to surface point sources. This is mainly because of the complex nature of the surface boundary condition. There is also a lack of understanding of how the soil water distribution is affected by the unsaturated hydraulic properties, which has sometimes resulted in non-optimal management and low water-use efficiency in drip irrigation systems. A better understanding of the interactions of irrigation method, soil type, crop root distribution, uptake patterns and rates of water applied, is needed to improve drip irrigation practices.

The formation of soil water regime under drip irrigation system on the scheme of planting one tree placed on the area for the tree from 20 to 40 $\mathrm{m}^{2}$.The simulation of the soil moisture under drip irrigation shown in figure (1) 


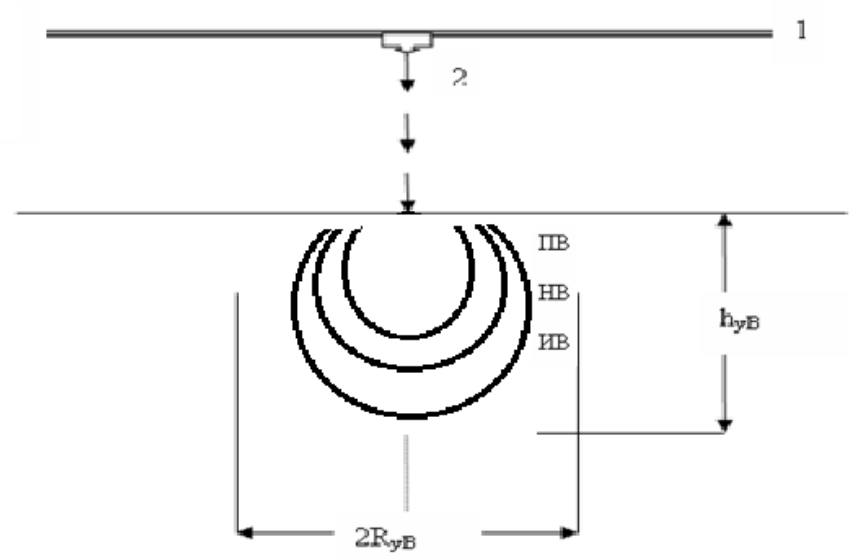

Fig. (1) Diagram of soil moisture under drip irrigation

Where:

1 - Irrigation tube

\section{2- Dripper}

$\Pi B$ - the moisture content in saturation

HB- the moisture content in holding capacity

ИВ - the moisture content in wilting point

ryb - the radius of the wet zones

hyb - depth of moisture

Moisture extraction by plant roots is one of the main factors affecting is the dynamics of moisture reserves in the humidified area. Consumption of soil moisture on transpiration of a tree determined by dependencies:

$$
\mathrm{Etr}=\mathrm{K} \sigma * \mathrm{Eo}^{*} \mathrm{F \kappa} \text { л /tree /day (1) }
$$

Where Etr is the rate of evaporation, depending on weather conditions, which calculated according to the formula:

$$
\mathrm{E}_{0}=0,0061(25+\mathrm{T})^{2}(1-0,01 \mathrm{a}) \mathrm{mm} / \text { day }(2)
$$

$\mathrm{T}$ - Temperature, c;

a - relative humidity;

$\mathrm{Fk}$ - area of the tree, $\mathrm{m}^{2}$;

$\mathrm{KB}$ - biological factor, for fruit trees between 0.35 to 0.55 . The moisture extraction by the roots of the tree of the wetted area calculated by the formula: 


$$
E_{t r}^{y 6}=\varepsilon E_{t r}(3)
$$

$$
\begin{aligned}
& \text { Where: } \varepsilon=0,9 /\left(1+\phi_{\text {нyb }} \frac{f_{y_{y b}}}{\phi_{y^{\prime}}} F_{y b}\right) \\
& \phi_{\text {нys }}=\varsigma_{\text {нyв } W_{\text {нyb }}} \phi_{y b}=\varsigma_{y b} W_{y s} \\
& f_{\text {нyb }}=2 \omega_{\text {нys }}-\omega^{2}{ }_{\text {нyb }} \omega_{\text {нyb }}=\frac{\left(\omega_{\text {Hys }}-B 3\right)}{(p-B 3)}(6) \\
& f_{y b}=2 \omega_{y b}-\omega_{y b}^{2} \omega_{y b}=\frac{\left(\omega_{y b}-B 3\right)}{(p-B 3)}(7)
\end{aligned}
$$

$W_{\text {нув }}$ - Volume of moisture in non-wetted area of the root zone:

$$
W_{\text {нys }}=W_{k}-W_{y b}
$$

$W_{y_{b}}$-Volume of moisture in wetted area:

$$
W_{y b}=F_{y b} h_{y b}
$$

$F_{y b}$ - Square wetted area, $\mathrm{m}^{2}$;

$h_{y b}$ - Depth of wetted zone, m;

$W_{k}$ - The amount of soil that holds the roots of the tree (volume root zone):

$$
W_{k}=F_{\partial} h_{k c}
$$

$h_{k c}$ - Thicknessof root layer, m;

$\varsigma_{\text {нyb }}$-Root density in non-wetted area;

$\varsigma_{y_{6}}$-Root density in wetted area;

$\omega_{\text {tyb }}{ }^{-}$- average soil moisture, fractional sizes in non-wetted area

The root zone, usually it decreases to fall, leading to an increase in $\varepsilon$, therefore, to growth in the selection of moisture from the humidified zone;

$\omega_{y_{6}}$ - Average of soil moisture in the wetted area, as a fraction of following formula:

$$
\omega_{\text {ув }}=\omega_{\min }+\frac{\left(\omega_{\max }-\omega_{\min }\right)}{3}
$$

$\omega_{\text {min }}$ - pre-irrigation soil moisture;

$\omega_{\text {max }}$ - soil moisture in the wetted area by the end of irrigation.

$\omega_{\text {min }^{-}}$usually administered in range $(0,6 \ldots 0,7)$ of holding capacity

In these calculations, humidity is transferred in the fraction of soil volume; 
$\mathrm{P}$ is the soil porosity; $\mathrm{VZ}$ soil moisture at which the tree roots will stop the moisture extraction, approximately $\mathrm{B} 3=(1,3 \ldots 1,5)$ of maximum hygroscopicity of the soil.

\section{NUMERICAL MODELS}

studies simulate subsurface drip irrigation (SDI) process as a line source (a lateral) (Ben-Gal et al., 2004; Skaggs et al., 2004; Patel, 2008; Bufon et al., 2011; Phogat et al., 2012), while others simulate SDI by means of a point source, as individual emitter (Lazarovitch et al., 2005; Provenzano, 2007; Kandelous and Šimůnek, 2010a, b). Some authors have also assessed the ability of modils to simulate water movement from surface drip irrigation systems (Assouline, 2001ץ... في المراجع ; Gardenas et al. 2005) but the number of studies on surface drip irrigation has been limited by the lack of appropriate boundary conditions (a problem which is now resolved by the introduction of version 2.0 in 2011). All of these studies carried out using either planar or axisymmetric two- dimensional flow domains.

By calculate the dependence of the factor $\varepsilon$ from the humidity of the soil is not wetted part of the root zone according to the formula (4) for the loamy black soil with

$$
\begin{gathered}
\mathrm{P}=0.48 \mathrm{~B}_{3}=0.13 \\
\mathrm{HB}=0.7 \mathrm{p}=0.7 \times 0.48=0.34 \\
\omega_{\min }=0.65 \mathrm{HB}=0.65 \times 0.34=0.22 \\
\omega_{\max }=\mathrm{HB}=0.34 \\
\omega_{\text {увср }}=\omega_{\min }+\frac{1}{3}\left(\omega_{\max }-\omega_{\min }\right)=0.22+\frac{1}{3}(0.34-0.22)=0.26 \\
\omega_{\text {ув }}=\frac{\left(\omega_{\text {увср }}-\mathrm{B} 3\right)}{(\mathrm{P}-\mathrm{B} 3)}=\frac{(0.26-0.13)}{(0.48-0.13)}=0,37 \\
\mathrm{f}_{\mathrm{yв}}=2 \omega_{\text {ув }}-\omega_{\text {ув }}^{2}=2 * 0.37-0.37 * 0.37=0.6
\end{gathered}
$$

Area per one tree, $F_{D}=24 \mathrm{~m}^{2}$, and the thickness of root layer $\mathrm{x}=1 \mathrm{~m}$, The volume of the root zone $\mathrm{wk}=24 \mathrm{~m}^{3}$, 
The area of the wetted zone $\mathrm{f}_{\mathrm{yB}}=4 \mathrm{~m}$, the depth of the wetted zone $\mathrm{h}=1$ $\mathrm{m}$, the volume of the wetted area $\mathrm{w}=1 \mathrm{~m}$, the volume is not wetted part of the root zone $\mathrm{w}_{\mathrm{нув}}=24-4=20 \mathrm{~m}^{2}$. Substituting in the formula (4) other known values, we get:

$$
\varepsilon=0.9 /\left(1+21.2 F_{\text {uyb }}\right)
$$

The moisture extraction by roots from the not wetted part of the root zone is calculated by the formula:

$$
E_{t r}^{y b}=(1-\varepsilon) E_{t r}
$$

In Fig. 2 the relation used to calculate the irrigation regime.

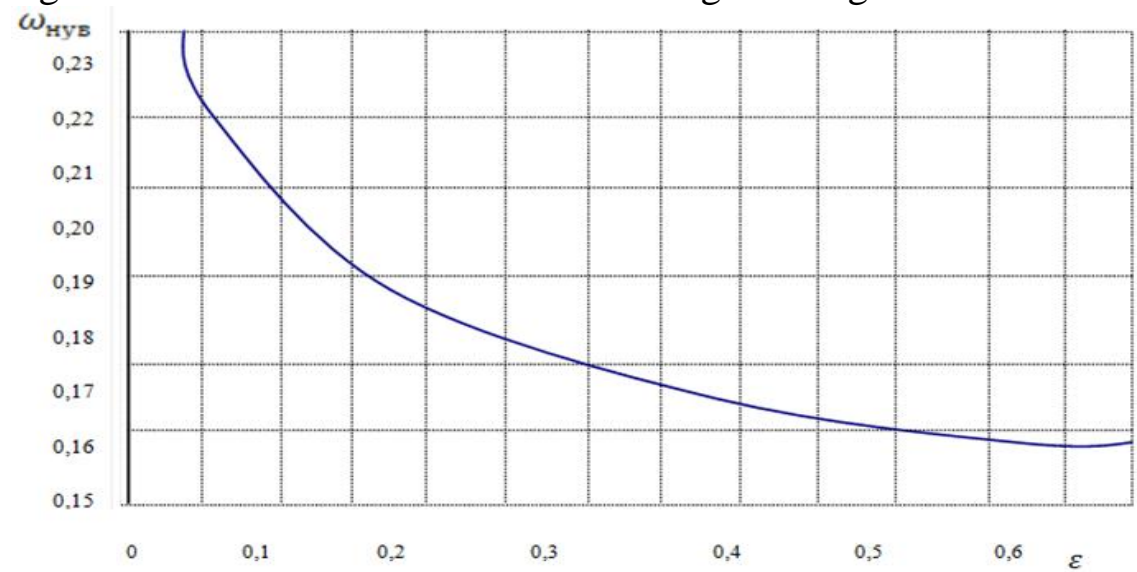

Fig. 2 the relationship between the $\omega_{\mu y 6}$ and $\varepsilon$

Evaporation from the soil surface in the garden in General small, as is usually used row crop system content rows, that is, the surface of the soil periodically cultivated by disc harrow to destroy weeds and reduce water loss to evaporation. the irrigation diameter wet spots does not exceed $0.2 \ldots 0.4 \mathrm{~m}$, but in balance the calculation of consumption for evaporation into account and accept it depending not only on the temperature and humidity of the surface air, but also on the degree of opacity of row spacing and moisture of the upper soil layer.

The evaporation from not wetted part of the soil surface for tree calculated by the formula:

$$
E_{f}^{H y b}=f_{f}^{H y b} E_{o} \frac{\left(F_{\partial}-F_{\kappa}\right)}{F_{\partial}} F_{\mu y b}
$$

and wetted surfaces:

$$
E_{f}^{y b}=f_{f}^{y b} E_{o} \frac{\left(F_{\partial}-F_{K}\right)}{F_{\partial}} F_{y_{b}},
$$


Where $f_{f}^{H y s}, f_{f}^{y b}$ - coefficients taking into account the effect of drying of topsoil on evaporation:

$$
f_{f}^{\mu y b}=\frac{\omega_{o}^{\mu y b}-\mu 2}{P-M 2} ; \quad f_{f}^{y b}=\frac{\omega_{o}^{y b}-M 2}{P-M 2}
$$

$\omega_{o}^{\text {kys }}, \omega_{o}^{y \beta}$ - average during the growing season the moisture content of the surface layers of the soil to wither a non-wetted parts of the square, respectively. Approximately you can take that $\omega_{o}^{\text {Hyb }}=\omega_{\text {min }}$, then for the conditions of the previous example, when the porosity of the soil $\mathrm{p}=0,48$ and maximum hygroscopicity

$$
\mathrm{M \Gamma}=0,1 f_{f}^{\text {Hyb }}=(0,22-0,1) /(0,48-0,1)=0,32 .
$$

on the wetted part of the surface moisture of the upper soil layers is approximately equal to $\omega_{o}^{y b}=\omega_{y_{b}}$, humidity in between watering, to the conditions of previous example

$$
f_{f}^{y b}=(0,26-0,1) /(0,48-0,1)=0,42 .
$$

In formulas (11) and (12) $F_{н у в}$ и $f_{y в}$-square wither a soul ù and wetted surfaces, respectively: $F_{н y b}+F_{y_{b}}=F_{\partial}$.

One of the main expense factors affecting the dynamics of moisture reserves in the humidified area is the horizontal outflow in the surrounding area, the amount of which depends on the control range of humidity watering. So, in loamy soils, while maintaining pre-irrigation moisture level of $0.60 \mathrm{HB}$, a horizontal outflow is approximately equal to the use of moisture for transpiration, and if you assign the glaze at higher humidity, the order of 0.70 to $0.80 \ldots \mathrm{HB}$, a horizontal outflow may be 1.2...1.7 times more transpiration.

When calculating the horizontal outflow of moisture from the wetted area must have wide to this process differs from conventional filtration, as occurs with incomplete saturation of pores with moisture. It is necessary to have the dependence of the coefficient of hydraulic conductivity from moisture:

$$
k_{\omega}=\alpha_{a n} k_{\Phi}\left[\frac{\left(\omega_{y b}-M 2\right)}{(p-M 2)}\right]^{5}
$$

$k_{\omega}$ - the coefficient of hydraulic conductivity, m/day

$k_{\omega}$ - filtration coefficient wetted soil layer, usually 
Determined in the field by means of dispensing, i.e. when the vertical filtering. In this connection it is necessary to take into account the possible anisotropy of the soil, that is, the dissimilarity values

Filtration coefficient in the vertical and horizontal directions, which can be significant for soils formed on loess. Therefore, in the formula (14) is introduced anisotropy factor $\alpha_{a n}$, loess-like soil it can be equal to $0,3 \ldots 0,6$.

In principle, to calculate the outflow from the wetted area necessary to solve the equation of motion of moisture to the partial saturation occurring in all three directions (three dimensional flow), which greatly complicates the calculation of the irrigation regime under drip irrigation, as it requires special programming and use of computers (such programs are developed by Golovanov at the Department of melioration and land reclamation MGUPP).the approximate outflow of water from the humidified area can be calculated by the formula Golovanov:

$$
\text { om }=\alpha_{6} m\left(1-e^{-t}\right)
$$

where $a$ is the coefficient considering the vertical outflow of water from the humidified zone in the underlying layers of the root zone, approximately

$\mathrm{a}=1,1 \ldots 1,2$;

$\mathrm{m}$ - irrigation rate, $1 /$ wood;

$$
\bar{t}=\frac{t}{\tau} \tau=R_{y b}^{2} c_{\omega} / k_{\omega}, \text { cyт }
$$

$\mathrm{t}$ is the time in days counted from the beginning of the irrigation; $R_{y_{6}}$ is the radius of the wetted area, m;

$c_{\omega}$-the coefficient of water capacity of the soil depending on its moisture content, and the capillary properties of the soil, $\mathrm{M}^{-1}$

\section{CONCLUSIONS}

Water distribution under drip irrigation systems is a three dimensional. It mainly depends on soil physical and hydraulic properties, crop evapotranspiration, drip irrigation system management and design parameters, such as emitter spacing, discharge rates, amount of water applied and target soil moisture deficit (depletion). All these factors have considered when designing drip irrigation systems. The influence of 
design parameters and management strategies on water distribution in different soil types is analytical or empirical models for predictions of the dimensions of the soil wetting patterns based on experimental results.

\section{REFERENCES}

Assouline S. 2002. The effects of microdrip and conventional drip irrigation on water distribution and uptake. Soil Sci. Soc. Am. J. 66(5): 1630-1636.

Ben-Gal A., Lazarovitch N., Shani U. 2004. Subsurface drip irrigation in gravel-filled cavities. Vadose Zone J. 3(4): 1407-1413.

Bufon V.B., Lascano R.J., Bednarz C., Booker J.D., Gitz D.C. Soil water content on drip irrigated cotton: comparison of measured and simulated values obtained with the Hydrus 2-D model. Irrig. Sci. 2011; 30 (4):259-273.

Cote C.M., Bristow K.L., Charlesworth P.B., Cook F.J., Thorburn P.J. Analysis of soil wetting and solute transport in subsurface trickle irrigation. Irrig. Sci. 2003; 22(3-4): 143-156.

Gardenas A, Hopmans J.W., Hanson B.R., Šimůnek J. Two dimensional modeling of nitrate leaching for various fertigation scenarios under micro-irrigation. Agric. Water Manag. 2005; 74(3): 219-242.

Kandelous M.M., Šimůnek J. Comparison of numerical, analytical and empirical models to estimate wetting pattern for surface and subsurface drip irrigation. Irrig. Sci. 2010a; 28: 435-444.

Kandelous M.M., Šimůnek J. Numerical simulations of water movement in a subsurface drip irrigation system under field and laboratory conditions using HYDRUS-2D. Agric. Water Manag. 2010b; 97(4): 1070-1076.

Lamm F.R., Ayars J.E., Nakayama F.S. Microirrigation for Crop Production - Design, Operation and Management. Elsevier Publications. 2007; 608.

Lazarovitch N., Šimůnek J., Shani U. System dependent boundary condition for water flow from subsurface source. Soil Sci. Soc. Am. J. 2005; 69 (1): 46-50. 
Lubana P.P.S., Narda N.K. Modelling soil water dynamics under trickle emitters - a review. J. Agric. Eng. Res. 2001; 78 (3): 217-232.

Patel N., Rajput T.B.S. Dynamics and modeling of soil water under subsurface drip irrigated onion. Agric. Water Manag. 2008; 95(12): 1335-1349.

Phogat V., Mahadevan M., Skewes M., Cox J.W.. Modelling soil water and salt dynamics under pulsed and continuous surface drip irrigation of almond and implications of system design. Irrig. Sci. 2012; 30(4): 315-333.

Provenzano G. Using HYDRUS-2D Simulation Model to Evaluate Wetted Soil Volume in Subsurface Drip Irrigation Systems. J. Irrig. Drain. Eng. 2007; 133 (4): 342-349.

Skaggs T.H., Trout T.J., Šimůnek J., Shouse P. J. Comparison of Hydrus2D simulations of drip irrigation with experimental observations. J. Irrig. Drain. Eng. 2004; 130(4): 304-310.

Skaggs T.H., Trout T.J., Rothfuss Y. Drip Irrigation Water Distribution Patterns: Effects of Emitter Rate, Pulsing, and Antecedent Water. Soil Sci. Soc. Am. J. 2010; 74(6): 1886-1896.

Vermeiren L., Jobling G.A. Localized irrigation. FAO Irrigation and Drainage Paper 36, FAO-UN, Rome, Italy. 1984; 203.

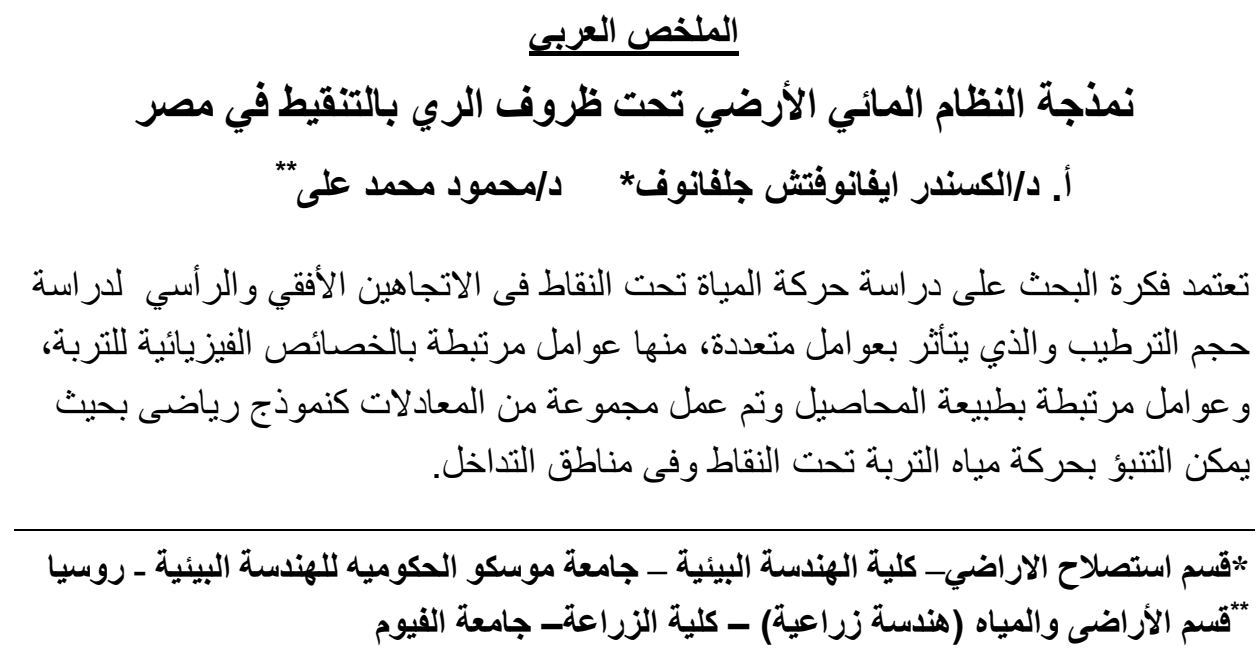

